\title{
Q methodology for assessing urban park values among stakeholders
}

\author{
K. B. Shuib ${ }^{1}$, H. Hashim² \& N. A. M. Nasir ${ }^{3}$ \\ ${ }^{I}$ Department of Landscape Architecture, \\ University Technology MARA, Malaysia \\ ${ }^{2}$ Department of Town and Regional Planning, \\ University Technology MARA, Malaysia \\ ${ }^{3}$ University Technology MARA, Malaysia
}

\begin{abstract}
Managers and planners may offer many recreational opportunities at the urban park but it does always depend on the users as to how they actually perceived the opportunities. These have been affecting their value system and influenced their attitude towards the setting. This study aimed to understand the value of urban park as perceived by three different stakeholders group linked to the urban park setting for urban park planning and management strategies. The application of $\mathrm{Q}$ methodology in this study was able to solve the diversity of interests among stakeholders by considering the fact that individual's opinions may be different from each other. The concourse used in this study based on the Malaysian Planning Guideline for Open Space and Recreation (2010) to explore the urban park setting that delivering the values. Then, $\mathrm{Q}$ sample photos were chosen to represent five elements in the urban park setting that are accessibility and traffic system, recreation facilities, landscape element, park furniture and other facilities. The photos were presented during $\mathrm{Q}$ sorting process and respondents were asked to sort the photos based on the questions given. Data analysis process was done using PQ method software that applied factor analysis technique and four values were produced which are natural value, sense of ownership and comfort value, recreational and health value and lastly, social value. This information was linked to the certain urban park setting for the improvement of urban park planning and management strategies for urban park.
\end{abstract}

Keywords: urban park, urban park values, community planning, $Q$ methodology, urban park stakeholders, urban park planning, urban park management. 


\section{Introduction}

Numerous publications and research has acknowledged the role of urban parks in increasing the quality of life of people. Managers and planners may have their own plan to continuously providing systematic urban park setting that would be able to deliver numerous values to the community. However, it always depends on the people on how they value the setting, how they react to it and how they could gain benefits from it. Stein et al. [1] stated that managers and planners would not be able to create the benefits and values by themselves but they can only provide the opportunities for people to gain the values at the site. Moreover, different people may have their own thoughts on the values gained from an urban park experience. Every person may perceive the setting in the different way thus resulting in a different recreational experience among them (as stated by Lime and Stankey [2]). Each opinion and viewpoint should be taken into consideration in developing a successful urban park system. Therefore, this study applied a systematic study known as Q methodology to assess the diversity of viewpoints among a stakeholders' group involved in urban park planning and management purposes.

\section{Objectives of the study}

This study primarily aimed to assess the value of urban parks as perceived by three different stakeholder groups to be utilized for urban park planning and management strategies. Therefore, four objectives were initiated to achieve the aim of the study:

1) To identify the concourse on urban park setting in delivering the values;

2) To understand the value of urban park as perceived by urban park users, urban community and professionals group;

3) To identify the most valued and the least valued of urban park setting;

4) To give recommendations for urban park planning and management strategies based on the values.

\section{Study area}

Y Lake Recreational Park is located in Batu Pahat town, Johor, Malaysia. The park plays a critical role in serving recreational opportunities among urban community as this is the only urban park in the town. Y Lake Recreational Park provides a wide range of recreational facilities such as facilities fitness, jogging track and open space. The park was managed by the local authority. As the number of population keep increasing from year to year, the role of the park becomes more critical. The demands and needs of community keep changing and the assessment on the stakeholders' value will be very important in ensuring the success of the park. 


\section{Implementation of Q methodology}

Q methodology is the research methodology applied in the study to assess respondents' personal opinions, interests and viewpoints. Q methodology was introduced by a psychologist named William Stephenson. Wilson [3] explained Q methodology as the study that combined qualitative and quantitative research to interpret subjectivity interests. Most importantly, Q methodology relies on the fact that everyone opinions are clearly different among each other and none of these opinions should be ignored and being forced to the one solution as R methodology used to operate. The application of Q methodology was growing rapidly in the field of communications, political sciences, recreation, social sciences, environmental research, personality assessment, psychiatric research and recently in health sciences. In conjunction with this study, the application of $\mathrm{Q}$ methodology involved five main steps as below:

\subsection{Developing the concourse}

In the $\mathrm{Q}$ methodology, the concourse defined as any relevant information, topics, or opinions towards the specific issue. In addition, the concourse can be explained as the collection of individual behavior towards the specific issue or events as explained by Ward [4]. A concourse can be any type of form; either statements, objects, photos or numbers. Photos were chosen as the representatives for concourse in the study to display the real condition of the urban park setting. The collection of concourse in the study were created based upon Malaysian Planning Guideline for Open Space and Recreation developed by Malaysian Department of Town and Country Planning [5]. This guideline is currently applied by the local

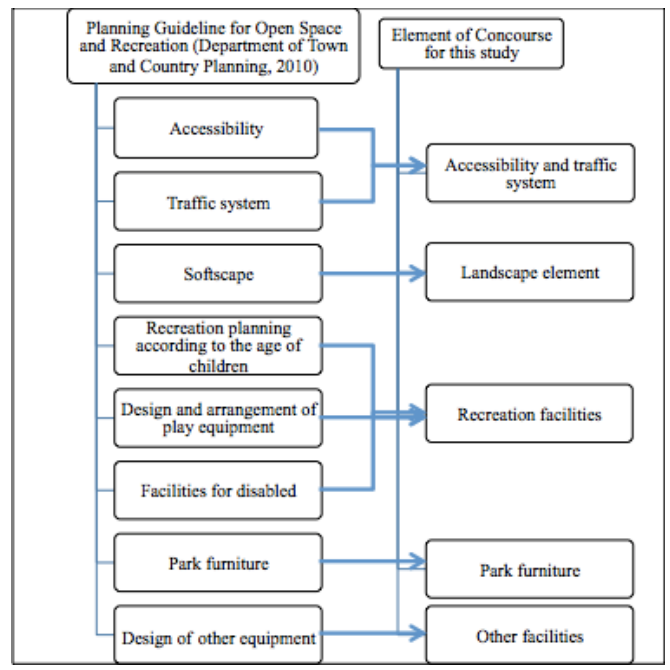

Figure 1: Concourse elements for the study based upon the Malaysian Guideline for Open Space and Recreation [5]. 
authority in developing and managing a local open space and recreation area. As this study focused on the local urban park, this guideline was therefore carefully analysed and five main elements were simplified as a guideline to collect as much as possible all the photos on the urban park setting. A total of 376 photos were captured as the concourse on urban park setting at the study area.

\subsection{Selecting the $Q$ sample}

Q sample was developed to represent the specific elements and was chosen from the collection of the concourse. Ward [4] stated that Q sample can be extracted from the concourse based on the literature review, media, discussion and interviews as long as the set was the representatives of the viewpoints, interests and opinions towards an issue. In the context of the study, Q sample was chosen based on the academic literature and interview session was done with a staff from Majlis Perbandaran Batu Pahat to carefully chose the best photos in representing the element on urban park setting. Additionally, other photos were also included in the set as long as the photos were considered as important to fulfill the elements in the urban park setting based upon Malaysian Planning Guideline for Open Space and Recreation [5]. The selection of 36 photos labeled number 1 until 36 are shown in figure 2 according to the elements on the urban park setting.

\subsection{Selecting the respondents called $P$ set}

Respondents who are also known as P set in the Q methodology were selected carefully that believed to be able to fulfill the aim of the study. The main highlight in Q methodology is the method does not require a large number of respondents as emphasized by Stenner [6] that the most important in the Q methodology is to assess the diversity of interests among respondents. Watts and Stenner [7] suggested a minimum ratio of respondents and the Q set is $2: 1$. In order to assess urban park values, three different stakeholders group were identified who were believed to get involved in any decision making process especially in the urban park planning and management process. There is a total of 45 respondents involved in the study; 15 people from urban park users, 15 people from urban community and another 15 people came from professionals group. Firstly, urban park users who were approached directly at the site. Next, urban community who living in the housing area nearby and also being approached at the mall. Lastly, professionals group who were identified to have park management related background as well as the staff from the local authority who are involved in the urban park management process. 


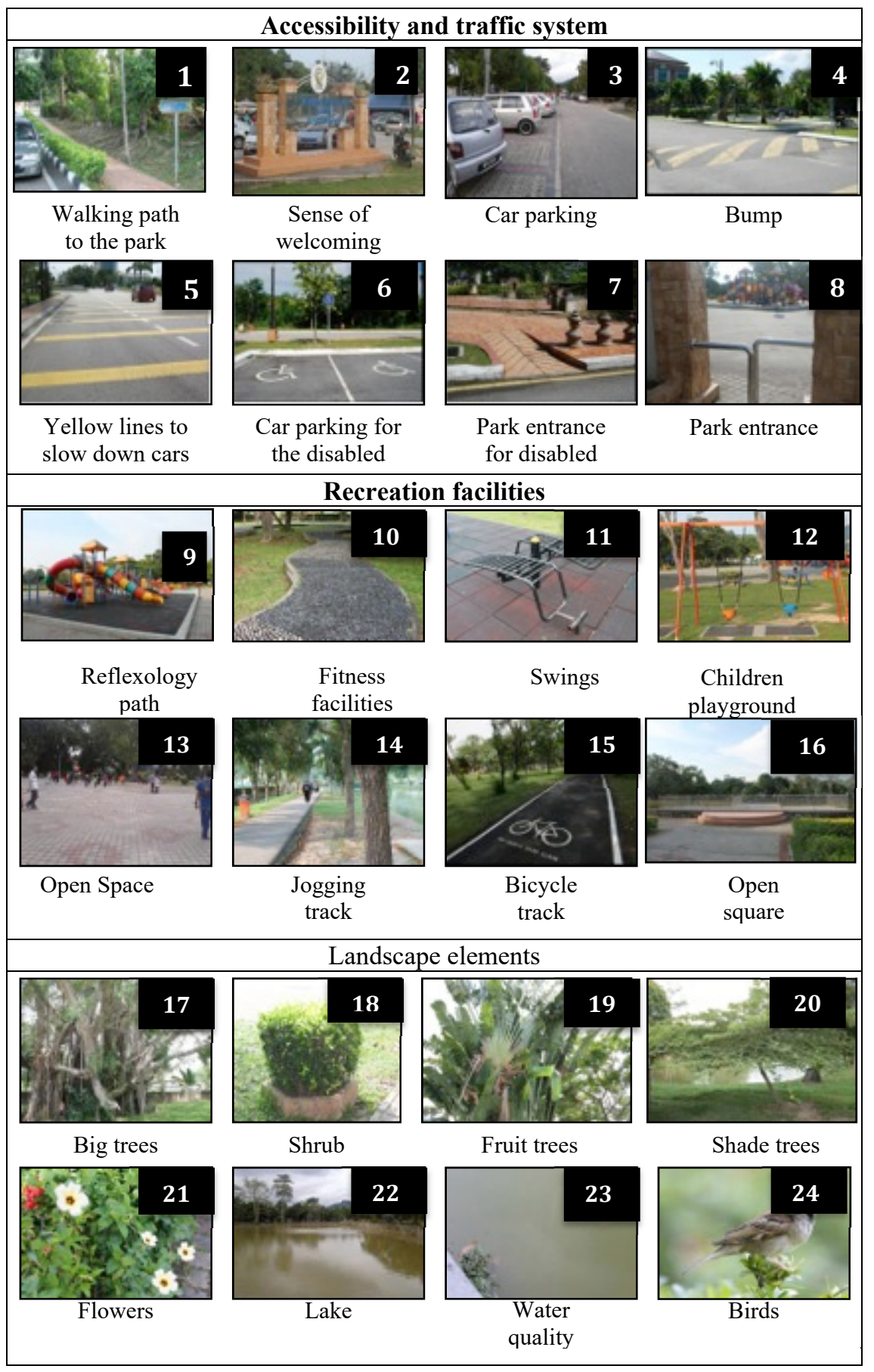

Figure 2: Q sample based on the urban park setting. 


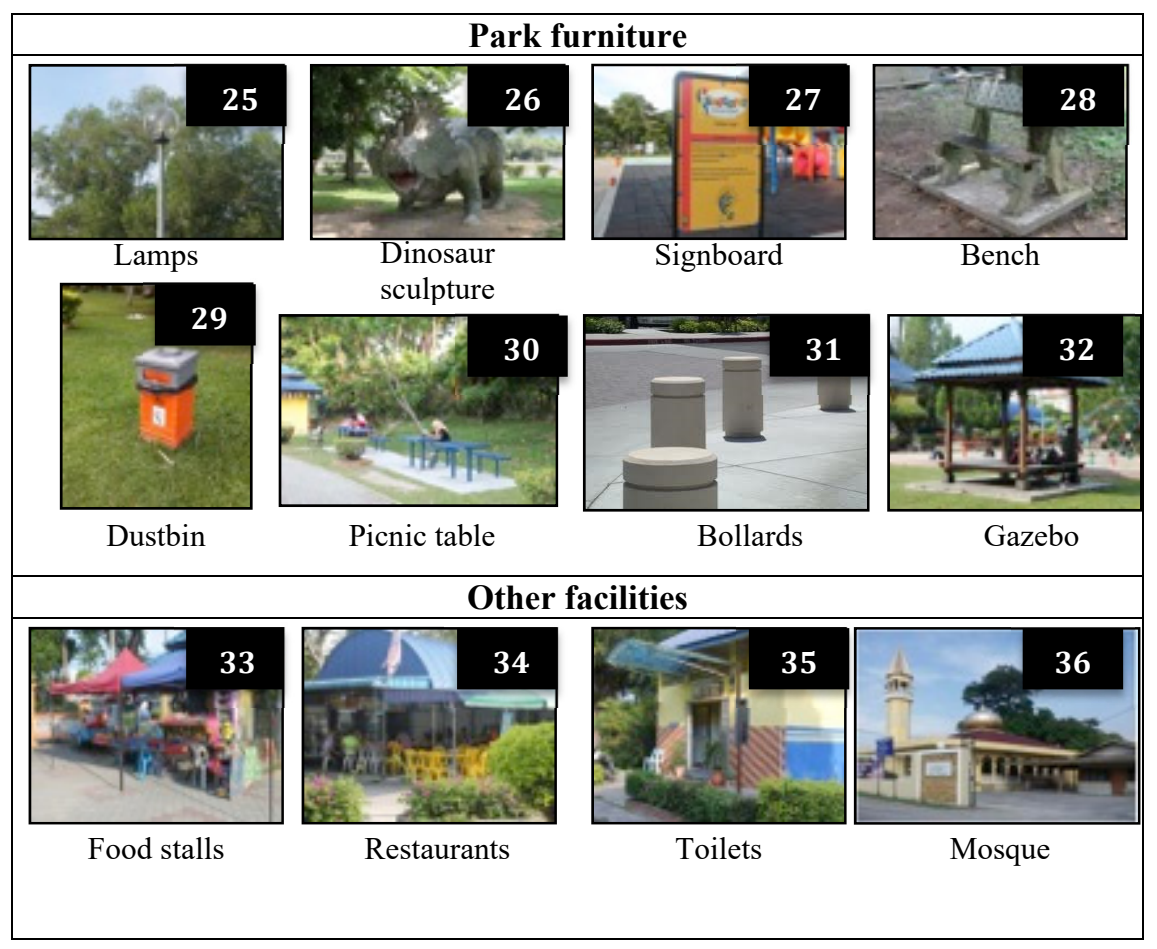

Figure 2: Continued.

\section{4 $Q$ sorting process or data collecting process}

The next step in Q methodology is the Q sorting process. Each respondent was approached carefully and most importantly, their permission was obtained before the process was conducted. Simple explanation was given to give a clear picture on how the process will be going on. However, there are few respondents were insisted to stop the process immediately and their response or answers was not taken into account. A questionnaire was prepared for the data collecting process. First section in the questionnaire asked about the demographic profile of respondents such as their age, race, employment status and the frequency of visiting urban park. Next, they were shown all the 36 photos that was identified as the Q set before and they were allowed to look all the photos roughly. Then, they were asked on the question, "How do you think this photo is very important for your urban park experience?". They were asked to distribute all the photos into three categories which are they agreed with, they disagreed with and the one they feel neutral or not sure with. After that, they were given a distribution scale and required them to place the photos according to the distribution scale. 


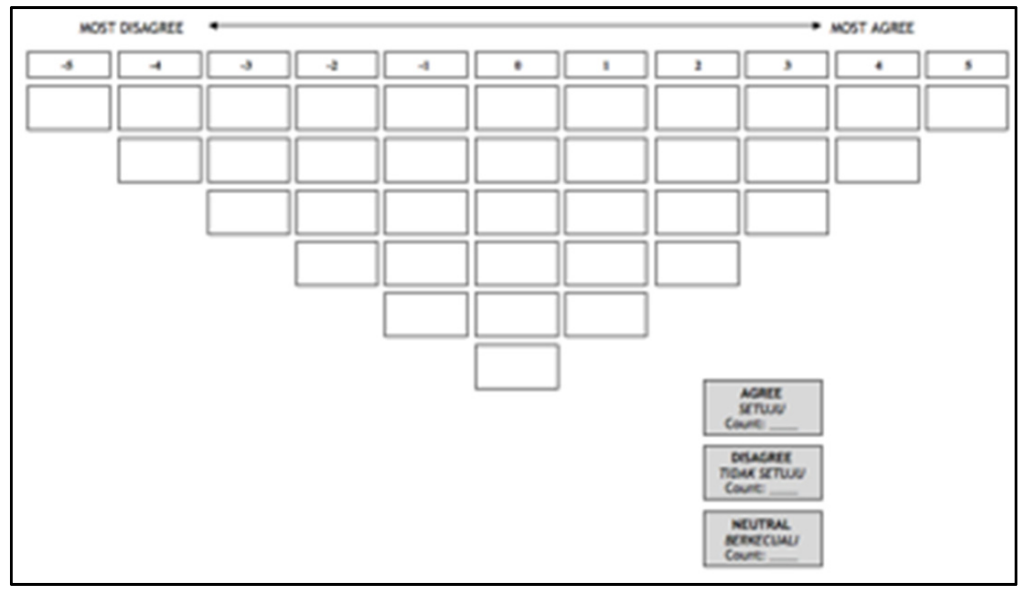

Figure 3: Forced choice distribution scale.

After all the photos were placed accordingly, respondents were given some time to carefully looking through their photos distribution and they were allowed to make any changes or amendments based on their thought. After the final decision, the number of the photos were recorded in the questionnaire. The last section in the questionnaire allowed respondents to write down their reasons for choosing certain photos to the certain scale. Open ended question was also provided in order to give chance for them to write any suggestions or opinions on how to improve their personal urban park experience.

\subsection{Data analysis}

PQMethod software was created specifically for the requirement of Q studies. It can be downloaded for free from Peter Schmolck's website. The software can be installed either in Windows, Mac OS X and Linus. After the installation, the name of the project was required and an external editor programme would be launched. Then, how many Q sample was asked and all the statement were required. As the study only used photos as the Q sample, the photo description was used according to the labeled number of the photos. Next, QEnter option asked to enter all the $\mathrm{Q}$ sorts data. Q sorts data means all the data collected from a respondent. A respondent was named with a desired code to easily identify the certain respondent. As for the study, the Q sort data were named according to the stakeholder group. For example, first respondent from urban park users group named as user001, first respondent from urban community group named as urban011 and so on. Then, the software asked to record the number of photos chosen for the distribution scale determined earlier. After all the 45 sorts were recorded, Q Principal Components Analysis (QPCA) option was chosen to construct eight factors automatically. These factors were later rotated to eliminate any ambiguities exists among these factors. This is very important to avoid two or more factors which are actually sharing the same views. Flagging the factors was also done to carefully identify which factors that respondents actually loading 
highly on it. After the flagging process, which factors were asked to include in the final analysis and QANALYZE would generate the final analysis of the Q sorts. The report on the final analysis can be found in the project folder and could be converted into Microsoft Word file. Either than qualitative analysis, quantitative research was also involved in $\mathrm{Q}$ methodology as the recorded answers from respondents was very important to interpret all the factors identified earlier.

\section{Result and discussion}

Data analysis process was conducted in order to retrieve few factors that may can be considered as significant. The four factors were identified and labeled as factor $\mathrm{A}$, factor $\mathrm{B}$, factor $\mathrm{C}$ and factor $\mathrm{D}$ as these factors were not interpreted yet. The extraction of four factors showed nine people were loaded highly on factor A, eleven people were loaded on factor $\mathrm{B}$, sixteen people were loaded on factor $\mathrm{C}$ and the remaining nine people were loaded on factor $\mathrm{D}$ regardless from which stakeholders group they were came from. Correlation matrix obtained from the process that showed how similar a factor between another factor. All the correlation score seems significant as it scored less than 0.5 as shown in the table below. However, factor $\mathrm{B}$ and factor $\mathrm{C}$ showed the highest correlation score but the interpretation process of the factor explained on why these two factors are different.

Table 1: Correlation matrix between each factor.

\begin{tabular}{|c|c|c|c|c|}
\hline Factor & A & B & C & D \\
\hline A & 1.0000 & 0.0545 & 0.1527 & -0.0715 \\
\hline B & 0.0545 & 1.0000 & 0.4576 & 0.0168 \\
\hline C & 0.1527 & 0.4576 & 1.0000 & 0.0660 \\
\hline D & -0.0715 & 0.0168 & 0.0660 & 1.0000 \\
\hline
\end{tabular}

Each factor was analysed carefully based upon the factor score obtained from each photo. The factor defined by the highest and lowest factor score of the photos followed by the interpretation process from primary data obtained during the $\mathrm{Q}$ sorting process. Answers from questionnaire and interviews recorded from respondents are playing important role in developing the theme of value for each factor. Therefore, four values were identified based upon the extraction of four factors earlier.

\subsection{Theme A: natural value}

This group of people chose the photos of shade trees and flowers as the most important element in maximizing their urban park experience. On the other hand, photos capturing other facilities such as food stalls and restaurants chosen as the least valued of urban park setting. These finding showed a strong concern on the cleanliness of the park and the high interests towards landscape element in the park. Nine respondents are included in this group and four of them came from 
the professionals group. Moreover, three people came from urban community and two people from urban park users group seems agreed on the natural value of the park. The park believed as a place to enjoy the beautiful landscape and natural element such as trees and flowers.

\subsection{Theme B: sense of ownership and comfort value}

Photo numbered 2 illustrated the entrance gate for the park received the highest score in this group. Additionally, other photo included in the accessibility and traffic system element illustrated the car parking facilities also received higher score. The selection of these two photos showed that people who are loading in this group valued accessibility and traffic system during their urban park experience. The selection of photos capturing image of toilet also received higher score helps in defining the factor. People in this group are likely to feel that they owned the park. They prefer for the park to be easily accessible and feel happy if the they could feel comfort as they enjoying recreational activities at the park. Other than that, photos shown images of big trees and fruit trees received the lowest score in this group. Respondents personally think that these types of trees should not be planted at the park as these trees can attract insects and animals thus may bring danger to the visitors.

\subsection{Theme C: recreational and health value}

The highest factor score received in this group is a photo displayed bicycle track facilities. Surprisingly, bicycle track actually did not exist in the study area. The photo was taken at Shah Alam Lake Garden in order to fulfill the requirement based upon the Malaysian Planning Guideline for Open Space and Recreation (2010). Additionally, photos of open space and children playground were also chosen as the most valued setting in this group. This fact strongly showed the recreational and health value among people who are loading in this group. The park was seen as the place to enjoy their recreational activities either active or passive thus contributing to their physical health.

\subsection{Theme D: social value}

Respondents who were associated with this group of theme listed a photo of gazebo as the most important element for urban park experience. Followed by a photo of open space and picnic table. The finding showed strong interests towards urban park furniture that encourage social interaction among urban park users. People in this group tend to value urban park as a place for them to hang out while strengthening their social relationship. It is a place for them to get close with family members and enjoying free time with children. However, photos of facilities for disabled people such as park entrance and car parking received the lowest score in this group. Based on the interview conducted, they feel that these facilities are not important since they never saw any disabled people came to the park. 


\section{Recommendations}

The recommendations were made based upon the result of the data supported by the primary data obtained during the data collecting process. Most of the recommendations were reflected back towards Malaysian Planning Guideline for Open Space and Recreation (2010) in order to fulfill the aim of the study; improvement for urban park planning and management strategies.

\subsection{Active recreation facilities should be increased}

Although bicycle track was not provided at the site, this setting received the highest score among respondents from urban park users and urban community group. Therefore, this issue should be taken seriously by professionals as people tend to value urban park as a place for them to get active thus contributing to their physical and mental health. More opportunities on active recreation should be provided to maximise the delivery of these benefits thus ensuring the successfulness of the park.

\subsection{The importance of well connecting of accessibility}

The study found out that well connecting of accessibility of the park is the main why people visiting the park. They would like to feel like they owned the park and they can get easily go to the park at any time without having any difficulties. Adequate car parking, public transportation and sense of welcoming should be improved to attract more visitors to the park. This should be taken seriously by managers and local authority as it influences the frequency of people visiting the park.

\subsection{Park as a place to encourage social interaction}

Gazebo, open space and picnic table should be provided more and maintained properly as these facilities were seen as the most important element during urban park experience. People tend to value urban park as a place for them to build their social interaction. Managers and planners should seize the opportunity for delivering the social values among community. People may come to the park to spend the quality time with children. At the same time, the design of the facilities may also encourage the interaction between urban park users thus strengthening the social relationship among neighbours.

\subsection{The facilities of food stalls and restaurants at the park}

The existence of food stalls and restaurants at the site may did not pleased by some respondents. They believed that the facilities only contribute to the trash problem and may affects the cleanliness of the park. People tend to value urban park because of its naturalness and the beautiful landscape. Managers and local authority should revise the location of the food stalls and restaurants at the park. 
Besides that, maintenance schedule should be improved to avoid any excessive trash at the park and ensure the cleanliness of the park at all the time.

\subsection{Facilities for disabled people}

Facilities for disabled people are included in the Malaysian Planning Guideline for Open Space and Recreation (2010) but the importance of these facilities did not aware by some stakeholders. People tend to think that these types of facilities are not important as they never saw any disabled people came to the park. Therefore, managers and local authority should initiate the ways to attract disabled people to come to the park and increase the awareness among community that disabled people also has the right to enjoy all the benefits offered by an urban park.

\subsection{The application of $Q$ methodology in assessing stakeholders' viewpoints}

Lack of information among different stakeholders group was always be the most common problem especially in local urban park management process. Managers and planners should realize that all the benefits of urban park should be able to gain by stakeholders. The differences of viewpoints among stakeholders may be solved from the application of Q methodology in assessing information for urban park planning and management decision making process. This study may be a starting point in conducting Q methodology for assessing viewpoints among stakeholders for urban park planning and management process.

\section{Conclusion}

Nowadays, the role of urban park becoming more important especially in an urban city. People tend to seek for a place to help them releasing their stress and urban park are believed to provide numerous value towards urban community. However, the value of urban park always depends on how people thought about it. How people valued urban park in their life will influence their attitude thus affecting the benefits of urban park among community. Moreover, managers and planners did not create the benefits of urban park by themselves but they can only provide the opportunities for people to gain benefits from them. This study promotes the application of Q methodology in assessing different demands and interests among three different stakeholders group which are urban park users, urban community and professionals group. The study aimed to understand on how stakeholders valued urban park to be utilized for urban park planning and management strategies. Malaysian Planning Guideline for Open Space and Recreation (2010) was used as the main guideline in developing photos for Q sample in the study. Q sample was the collection of photos on urban park setting that were presented in front of respondents during data collection process. Data collection process required respondents to rank order the photos according to the distribution scale provided. Four theme of values were found in the study and each theme were analysed based upon the factor score received by each photo. The interpretation process was done based on the answers and recommendations were made to improve local urban park planning and management strategies. 


\section{References}

[1] Stein, T.V., Anderson, D.H. \& Kelly, T., Using stakeholder's values to apply ecosystem management in an upper midwest landscape. Environmental Management, 24(3), pp. 399-413, 1999.

[2] Lime, D.W. \& Stankey, G.H., Carrying capacity: maintaining outdoor recreation quality. Recreation Symposium Proceeding, Syracuse, New York, 1971.

[3] Wilson, I.B., Person-place engagement among recreation visitors: a q method inquiry, Doctoral dissertation, Oklahoma University, 2005.

[4] Ward, W., Q and you: the application of q methodology in recreation research. Proceedings of the 2009 Northeastern Recreation Research Symposium, Southern Illinois University, 2009.

[5] Department of Town and Country Planning, Garis panduan pembangunan tanah lapang dan rekreasi, www.townplan.gov.my, 2010.

[6] Stenner, P., What is Q methodology?, www.ccsr.ac.uk, 2005.

[7] Watts, S. \& Stenner, P., Doing Q methodological research: theory, method and interpretation, Sage Publication, London, 2012. 